Esta revista forma parte del acervo de la Biblioteca Jurídica Virtual del Instituto de Investigaciones Jurídicas de la UNAM www.juridicas.unam.mx

\title{
Las elecciones de Cherán: usos y costumbres excluyentes
}

\author{
Mauricio I. Ibarra* \\ Jorge G. Castillo Vaquera**
}

\section{Sumario:}

I. Introducción

II. Antecedentes de las elecciones por usos y costumbres

III. Tradición y federalismo a debate

IV. Resolución jurisdiccional

V. Conclusiones

VI. Bibliografía

* Licenciado en derecho por la Universidad Autónoma Metropolitana y Maestro en economía y política internacional por el Centro de Investigación y Docencia Económicas.

** Licenciado en política y gestión social por la Universidad Autónoma Metropolitana y Doctor en ciencia política por la Universidad de la Sorbonne Nouvelle, París III, Francia.

D. R. @ 2014. Universidad Nacional Autónoma de México-Instituto de Investigaciones Jurídicas.

Revista Mexicana de Derecho Electoral, núm. 5, enero-junio de 2014, pp. 263-283, 


\section{Introducción}

La comunidad purépecha de San Francisco Cherán existe desde la época prehispánica y existen registros escritos que dan cuenta de ello desde el siglo XVI. En la actualidad, el municipio de Cherán en el estado de Michoacán se encuentra enclavado en medio de la Sierra Purépecha, abarcando una superficie de 27000 hectáreas de bosques de coníferas de los cuales, como afirman los propios pobladores, en la actualidad sólo les quedan 7000 hectáreas, debido a la tala clandestina. De acuerdo con datos del Censo General de Población 2010, el municipio cuenta con 18141 habitantes. De ese total, conforme al listado nominal de electores del Registro Federal de Electores del Instituto Federal Electoral, en el municipio se encuentran inscritos 13608 ciudadanos.

En razón de su situación geográfica, el municipio se encuentra en una zona que no sólo encierra una riqueza natural inmensa sino que también está ubicada en medio de las rutas de producción y tráfico de estupefacientes. Ello ha propiciado la presencia de grupos del crimen organizado, ligados al tráfico de drogas, así como a la tala clandestina llevada a cabo por bandas de talamontes.

Esta combinación de factores ha ocasionado que al interior del municipio la violencia haya ido en escalada y que la naturaleza de los conflictos pierda su punto de partida, transformándolos en una verdadera guerra por mantener, a cualquier costo, un territorio que se antoja estratégico para el crimen organizado.

Ante la magnitud de los problemas de violencia enfrentados en el municipio de Cherán, hasta antes de 2011, las autoridades electas del lugar (presidente municipal y cabildo), se vieron rebasadas en su capacidad de gobernar, produciendo un hartazgo paulatino entre los pobladores de la comunidad. El sentir de algunos de ellos atribuía su atomización interna a la influencia de los partidos políticos, así como a agentes externos a la comunidad y a sus costumbres.

En términos de la organización de la comunidad, desentrañar el origen de estos elementos perturbadores, contribuyó a reforzar su unificación a favor de la defensa de sus intereses, generando, al mismo tiempo, una conciencia de autodefensa, autogestión y desconfianza hacia todo aquello que viniera del exterior; en particular, en lo rela- 
cionado a partidos políticos, elecciones y autoridades públicas ligadas a la política partidista y sus intereses.

El principio de autogestión surgió precisamente ante la inoperancia y la falta de identidad de la comunidad con la autoridad pública. En abril de 2011 se agudizaron los enfrentamientos sostenidos entre comuneros del municipio de Cherán con talamontes y grupos de delincuentes. A fin de protegerse, los habitantes de los barrios donde se dieron los enfrentamientos empezaron instalando fogatas en cada barrio para cuidar a la comunidad de los ataques de integrantes de la delincuencia organizada, evolucionando de manera tal que decidieron expulsar y desconocer a la policía y demás autoridades, estableciendo así una forma de gobierno alternativa.

Esta nueva estructura tiene como primer escalón las fogatas (integradas por unos cuantos pobladores), como segundo las asambleas de barrios (con mayor número de habitantes), y por último las asambleas generales donde se discuten y toman las decisiones de la comunidad. A través de estas asambleas se habían nombrado diversas comisiones integradas por representantes de todos los barrios de la comunidad.

Así, ante la crisis de inseguridad, los habitantes de Cherán reemplazaron a las autoridades que fueron incapaces de dar una respuesta efectiva en contra de las amenazas que aquejaban a la comunidad. Los pobladores, en este sentido, decidieron tomar la seguridad de la comunidad en sus propias manos, llevando a cabo una serie de acciones encaminadas a preservar la seguridad y hacer hermética la comunidad, a través de la instalación de barricadas, rondines y comités de seguridad comunales. En cierta manera, lo que la comunidad se propuso fue sustituir a los elementos del Estado, ante su incapacidad e inoperancia.

Es en ese contexto que debe entenderse el rechazo de la comunidad a participar en las elecciones del 13 de noviembre de 2011 para elegir gobernador, diputados locales y ayuntamientos en el estado de Michoacán. Como se verá más adelante, esta actitud, además de poner en entredicho la jornada comicial, lo hizo invocando los usos y costumbres propios de las comunidades indígenas, situación no prevista en la Constitución ni en las leyes secundarias michoacanas. De ahí que la resolución del caso se haya dado en el ámbito federal. 


\section{Antecedentes de las elecciones por usos y costumbres}

Los diferentes movimientos sociopolíticos, protagonizados por pueblos y comunidades indígenas conocieron su auge a partir de la reivindicación de sus propios derechos, políticos, sociales, económicos, agrarios, entre otros, los cuales han sido históricamente relegados y que sólo a través de luchas sociales han podido colocar en el centro del debate de la agenda gubernamental y política.

Como sostienen Arenas (2003) y Armenta (2010): "Los permanentes reclamos de los pueblos indígenas y la prominencia internacional que adquirió el reconocimiento de sus derechos, han llevado a una importante modificación de las coordenadas en las que se desarrollan los procesos políticos y sociales en las etnias del país".

En 1992 se llevó a cabo una reforma constitucional al artículo 4o. de la Constitución que a la letra dice: "La Nación mexicana tiene una composición pluricultural sustentada originalmente en sus pueblos indígenas.... ${ }^{2}$ En realidad, aun cuando la Constitución reconoce las diferencias entre las etnias y el resto de los ciudadanos, su objetivo central es proteger el interés general y la igualdad entre los individuos. He aquí uno de los puntos más discutibles de toda reforma focalizada en determinados grupos sociales. Este reconocimiento se traduce en distintas disposiciones legales que garantizan la aceptación de las instituciones tradicionales indígenas, así como de sus usos y costumbres.

Uno de los movimientos indígenas más emblemáticos fue el que protagonizó en Chiapas el llamado Ejército Zapatista de Liberación Nacional (EZLN), cuando el 1o. de enero de 1994 se levantó en armas contra el gobierno federal, bajo el mando del subcomandante Marcos, arrojando luz a una larga historia de agravios, abusos, racismo, exclusión y marginación de los pobladores originarios de México. A partir del EZLN, los habitantes de México voltearon su mirada hacia los indígenas, para darse cuenta del desahucio y las condiciones paupérrimas bajo las que vivían estos pueblos.

1 Arenas Bátiz, Emilio, Reflexiones en torno a la integración y prueba del derecho electoral consuetudinario indígena, México, IFE, 2003, pp. 158 y ss.

2 Fix Fierro, Héctor, Los derechos políticos de los mexicanos, 2a. ed. México, UNAM, Instituto de Investigaciones Jurídicas, 2006, p. 64. 
Esta revista forma parte del acervo de la Biblioteca Jurídica Virtual del Instituto de Investigaciones Jurídicas de la UNAM

El pasamontañas que portaban representaba un "espejo orientado hacia los mexicanos"; "a pesar de que al principio no se trataba sino de un accesorio más, el pasamontañas adquirió una función de máscara, para ocultar la identidad personal y dar vida a una figura a la cual los desheredados, y más allá de ellos, todos los mexicanos y todas las personas que claman por la justicia, sin importar sus diferencias, pudieran identificarse". "Nosotros indígenas éramos invisibles. Fue necesario tapar nuestras caras para que nos vean". ${ }^{3}$

El simbolismo del movimiento del EZLN le hizo ganar por algún tiempo reconocimiento dentro y fuera del país. De la mano de su corriente ideológico-política, sirvió como referente para muchos movimientos sociales más, tanto en el ámbito de la lucha social, como de la lucha armada. ${ }^{4}$

También emergieron movimientos al interior de las comunidades indígenas, de reivindicación de sus derechos, exigiendo el reconocimiento del Estado para garantizar la autodeterminación de los pueblos. Éste sería el primer antecedente de los gobiernos por usos y costumbres, que en principio fueron impulsados en el ámbito local, hasta 2001 año en el que se aprobó la primera ley federal en materia indígena.

La ley mexicana permite que, bajo ciertas condiciones, la elección de cargos municipales se realice sobre la base de procedimientos de decisión ancestralmente utilizados por las poblaciones indígenas locales y el derecho indígena conocido como "usos y costumbres", por lo que se reconoció por primera vez la composición pluriétnica y pluricultural de la nación mexicana, a la vez que se formulaba también un primer reconocimiento a las costumbres y usos jurídicos propios de los pueblos y comunidades indígenas.

El reconocimiento de este derecho y de las instituciones tradicionales indígenas, muchas de las cuales tienen una realidad indudable, ha avanzado en México en los últimos años, aunque es todavía incipiente.

3 Cfr. Renard, Marie-Christine, 1994, "Le Chiapas est aussi le Mexique, neo-zapatisme et changement politique", Cahiers des Amériques Latines, núm. 17, París, Institut des Hautes Etudes de l'Amérique Latine (IHEAL).

${ }^{4}$ Sobre la influencia del EZLN sobre otros movimientos indígenas, especialmente en Oaxaca, véase, por ejemplo, Recondo, David, "Usos y costumbres y elecciones en Oaxaca. Los dilemas de la democracia representativa en una sociedad multicultural", TRACE (Travaux et Recherches dans les Amériques du Centre), CEMCA, núm. 36, diciembre de 1999, pp. 85-101. 
En el nuevo texto constitucional se aborda explícitamente el reconocimiento de su libre determinación y autonomía, lo que incluye sus formas propias de gobierno.

Siguiendo la fracción III del apartado A del artículo 2o. constitucional, se establece la facultad para elegir de acuerdo con sus normas, procedimientos y prácticas tradicionales, a las autoridades o representantes para el ejercicio de sus ¿formas propias? de gobierno interno, garantizando la participación de las mujeres en condiciones de equidad frente a los varones, en un marco que respete el pacto federal y la soberanía de los estados. ${ }^{5}$

El reconocimiento y regulación de estos derechos en los municipios, implica que el texto constitucional remita a las Constituciones y leyes de las entidades federativas, determinado que la reglamentación local tendrá el propósito de fortalecer la participación y la representación política de conformidad con sus tradiciones y normas internas.

Como ejemplo de esta regulación de las modalidades por usos y costumbres, podemos mencionar al estado de Oaxaca (Recondo, 1999), excepcional toda vez que en él habitan pueblos cuya tradición, historia y composición territorial es símbolo de la identidad en la diferencia y de la unidad en la pluralidad. Además de contar con la mayor riqueza ambiental, étnica y lingüística del país, por la presencia de sus pueblos indígenas, Oaxaca es la entidad federativa con el mayor número de municipios (570), concentrando el $23 \%$ del total nacional.

La necesidad de trazar el futuro jurídico de una pluralidad necesaria, en apego a los avances en materia de derechos políticos de los pueblos indígenas, se ha integrado al derecho electoral en los principios nominativos de las prácticas democráticas seguidas por las comunidades para renovar sus órganos de gobiernos locales, por cuyo carácter consuetudinario son conocidas como de usos y costumbres.

Del total de municipios oaxaqueños, 418 municipios se rigen bajo el sistema de usos y costumbres, y 152 siguen el régimen de partidos políticos. Esta situación está prevista y regulada en la Constitución política, la ley orgánica municipal y el código electoral locales (Recondo, 1999; Armenta Ramírez, s. f.).

En 1995 se reformó el artículo 25, penúltimo párrafo, de la Constitución estatal que dice: "La ley protegerá las tradiciones y prácticas democráticas de las comunidades indígenas, que hasta ahora han

5 Diario Oficial de la Federación, 14 de agosto de 2001. 
utilizado para la elección de sus ayuntamientos". Con fundamento en esta disposición se dieron dos reformas al Código de Instituciones Políticas y Procesos Electorales del Estado (CIPPEO), de 1995 y 1997, las cuales establecieron las reglas que rigen las elecciones por usos y costumbres (artículos 109-125). De acuerdo con dichas disposiciones, los municipios que cumplan determinadas condiciones pueden acogerse al régimen de elecciones por usos y costumbres, por oposición a las elecciones con la participación de los partidos políticos (Calvo y Cienfuegos, 2006; Armenta Ramírez, s. f.; Recondo, 1999).

El CIPPEO dispone, además, que los ayuntamientos electos bajo normas de derecho consuetudinario no tendrán filiación partidista (artículo 118), y confiere al Instituto Electoral local la facultad de resolver las controversias que se presenten, previa búsqueda de conciliación entre las partes (artículo 125). En Oaxaca, la Constitución estatal y la ley de derechos de los pueblos y comunidades Indígenas contienen avances notables en materia indígena respecto al contexto nacional (Calvo y Cienfuegos, 2006; Armenta Ramírez, s. f.; Recondo, 1999).

Como se mostrará en el siguiente caso, más que a una tendencia federal, las modalidades de la aplicación y de la convivencia que generan este tipo de elecciones por usos y costumbres responden, ante todo, a una dinámica local, y ello puede verse en el surgimiento de las leyes locales, como en el caso de Tlaxcala.

En 1985 se introduce en Tlaxcala lo que podríamos llamar el "principio de representación comunal y territorial” dentro del ayuntamiento, con los "regidores de pueblo". Los delegados o agentes del ayuntamiento en los pueblos rurales y en los barrios urbanos ya no son designados por el ayuntamiento sino electos por la comunidad. Al mismo tiempo, son incorporados como regidores al ayuntamiento ("regidores de pueblo") (Armenta Ramírez, s. f.).

El ayuntamiento está compuesto por tres tipos de regidores: 1) los de mayoría relativa; 2) los de representación proporcional, y 3) los del pueblo (representación comunal y territorial). El ayuntamiento amplía el número de sus regidores según la cantidad de regidores de pueblo, aunque permanezcan en número fijo los regidores de mayoría y de representación proporcional.

El efecto trascendental de la introducción de la "representación comunal y territorial" en el ayuntamiento tlaxcalteca se refleja en que ahora las entidades que forman parte del municipio (pueblos rurales, comunidades urbanas) están representadas en el órgano de gobierno municipal. 
Esta revista forma parte del acervo de la Biblioteca Jurídica Virtual del Instituto de Investigaciones Jurídicas de la UNAM

En 1995 se introduce en la Constitución del estado de Tlaxcala la figura de la "presidencia municipal auxiliar", donde el "presidente municipal auxiliar" sigue perteneciendo al ayuntamiento como "regidor de pueblo", pero con atribuciones y recursos municipales, legislados por el Congreso estatal, que ejercen en su ámbito local. ${ }^{6}$

La Constitución de Tlaxcala en su artículo 87, fracción IV, inciso b, reconoce dos sistemas de elección de presidentes de Comunidad en el estado: por el principio de sufragio universal, libre, directo y secreto y la modalidad de usos y costumbres. Con el reconocimiento al sistema de usos y costumbres como un método de elección, el Estado respeta las formas de organización política y social propias de las comunidades que practican este método, concediéndoles a los presidentes de Comunidad electos bajo este sistema, las mismas atribuciones que a los electos por el principio de sufragio universal.

Antes de las reformas en materia electoral, las comunidades que practicaban este método de elección no estaban obligadas a informar sobre sus elecciones de presidentes de Comunidad al Instituto Electoral de Tlaxcala y éste, a su vez, no estaba facultado para intervenir en las elecciones por usos y costumbres. Sin embargo, con la legislación electoral vigente y las reformas al artículo 116 de la ley municipal de Tlaxcala, se faculta y se obliga a dicho Instituto a tener presencia en las asambleas, así como a dar asistencia técnica, jurídica y logística que se requiera. Existe un catálogo que permite identificar a 98 comunidades que eligen a sus presidentes por el sistema de usos y costumbres, en 24 de los 60 municipios que integran el estado de Tlaxcala.

La legislación en Chiapas busca un compromiso entre el sistema de usos y costumbres y el régimen de partidos. El artículo 6o. de la ley de derechos y cultura indígena "reconoce y protege a las autoridades tradicionales de las comunidades indígenas, nombradas por consenso de sus integrantes y conforme a sus propias costumbres". Estas autoridades no sólo incluyen las electas para efectos de la integración del correspondiente ayuntamiento. ${ }^{7}$

6 Espinoza Ponce, Farideh A., "Usos y costumbres: elecciones en Tlaxcala”, Con ciencia política, núm. 11, 2006, pp. 110-125.

7 Para un análisis profundo del caso de las elecciones por usos y costumbres en Chiapas, véase: Viquiera y Sonnleitner, 2000; Sonnleitner, Willibald, 2000, Elecciones en Los Altos de Chiapas, 1991-1998, Centro de Investigaciones y Estudios Superiores en Antropología Social, entre otros. 
Por su parte, el artículo 37, fracción XV, del código electoral señala como obligación de los partidos:

En los distritos y municipios con población predominante indígena, los partidos políticos preferirán registrar candidatos a ciudadanos indígenas, previo proceso de selección interna, respetando sus tradiciones, usos y costumbres; y que en las planillas para la integración de los ayuntamientos, la población indígena de esos municipios estén preponderantemente representadas.

Las Constituciones de Jalisco, Veracruz, Campeche y Quintana Roo reconocen los derechos de los pueblos indígenas; las leyes electorales de Guerrero, Puebla y Sonora, a pesar de reconocer los usos y costumbres en materia electoral, no determinan recursos o medios de impugnación para el caso de que se presente alguna violación a los derechos políticos electorales de los integrantes de las comunidades indígenas (Armenta Ramírez, s. f.).

\section{Tradición y federalismo a debate}

Uno de los problemas más complejos que plantea el estatus legal del sistema de usos y costumbres es que su vigencia establece una diferenciación entre los ciudadanos, así sea con la intención de generar condiciones de equidad. Se trata también de una de las consideraciones que se hacen en torno de las llamadas "acciones afirmativas", cuya premisa central consiste precisamente en distinguir y favorecer a un sector relegado socialmente, discriminado o excluido a fin de generarle mayores oportunidades.

Son acciones que pretenden:

... establecer políticas que dan a un determinado grupo social, étnico, minoritario o que históricamente haya sufrido discriminación a causa de injusticias sociales, un trato preferencial en el acceso o distribución de ciertos recursos o servicios así como acceso a determinados bienes. El objetivo 
Esta revista forma parte del acervo de la Biblioteca Jurídica Virtual del Instituto de Investigaciones Jurídicas de la UNAM

es mejorar la calidad de vida de los grupos desfavorecidos y compensarlos por los perjuicios o la discriminación de la que han sido víctimas. ${ }^{8}$

A pesar de lo anteriormente asentado, es una realidad que una parte de las normas derivadas del sistema de usos y costumbres está lejos de funcionar como el mandato constitucional lo establece. Por el contrario, casos como el de Eufrosina Cruz, mujer indígena oaxaqueña que, como hemos dejado establecido en un texto reciente, “... plantea un conflicto entre los postulados del derecho consuetudinario y del derecho constitucional, pues la comunidad al prohibir la participación electoral de la mujer indígena vulnera sus derechos políticos y, en consecuencia, conculca el principio constitucional de igualdad de género" (Castillo e Ibarra, 2012), en virtud de que Eufrosina fue excluida por su comunidad, al amparo del gobierno por usos y costumbres, de la elección para presidente municipal de Santa María Quiegolani.

Hay que subrayar que en la tradición legal mexicana referida a la realización de comicios en contextos socio-culturales de usos y costumbres, ésta se encuadra en primer término dentro del marco constitucional local que precisa el reconocimiento explícito de la diferencia entre los ciudadanos de comunidades o etnias indígenas y el resto de los gobernados, como una medida afirmativa para evitar la discriminación.

Como se verá en detalle en el epígrafe siguiente, para el caso de Cherán, Michoacán, el Tribunal Electoral del Poder Judicial de la Federación (TEPJF) dictó una sentencia sui generis que, a nuestro parecer, no sólo pone en entredicho las normas del pacto federal referidas al órgano competente para legislar sobre la adopción del sistema de usos y costumbres en comunidades indígenas, sino también, al hacerlo, afectó los derechos ciudadanos de parte de los habitantes del municipio. Si bien es cierto que el TEPJF es la máxima autoridad federal en materia jurisdiccional electoral, históricamente el federalismo mexicano había otorgado a las soberanías locales esa prerrogativa.

Este caso marca un hito en la materia porque convalida, por un lado, un acto que en el plano local estaba considerado como fuera de la ley (suspensión de elecciones constitucionales) y, por otro lado, da

${ }^{8}$ Véase, Sistema de monitoreo de la protección de los derechos y la promoción del buen vivir de los pueblos indígenas de América Latina y el Caribe, en $w w w$.fondoindige na.org (consultado el 30 de agosto de 2012). 
Esta revista forma parte del acervo de la Biblioteca Jurídica Virtual del Instituto de Investigaciones Jurídicas de la UNAM

sustento legal para que se realicen elecciones por usos y costumbres en el municipio de Cherán.

La existencia de estas controversias de naturaleza política y jurídica nos lleva a revisar de manera más detallada la resolución dada por la Sala Superior del TEPJF que, como se verá a continuación, originó una batalla por la jurisdicción electoral entre las diferentes autoridades locales y federales, cuestionando de facto el sistema de competencias propio del federalismo.

\section{Resolución jurisdiccional}

Faltando menos de seis meses para celebrar elecciones locales en Michoacán, el 1o. de junio de 2011 los habitantes de Cherán se reunieron en una asamblea general en la cual se tomaron varias determinaciones. Por principio de cuentas acordaron celebrar elecciones para nombrar a sus autoridades municipales bajo el sistema de usos y costumbres. Al mismo tiempo, decidieron abstenerse de participar en el proceso electoral local del 13 de noviembre para elegir gobernador, diputados locales y presidentes municipales, además de impedir que las autoridades electorales ejercieran sus facultades en esa demarcación territorial. A los pocos días, el 6 de junio, dicho acuerdo fue hecho del conocimiento del Consejo General del Instituto Electoral del Estado de Michoacán (IEEM). Ante la falta de respuesta pronta del IEEM, el 26 de agosto algunos de los habitantes del municipio de Cherán urgieron a ese órgano a manifestarse respecto al derecho de la comunidad a utilizar los usos y costumbres para nombrar a sus autoridades.

La petición de la comunidad buscaba modificar el régimen jurídico ordinario regulador de elecciones de integrantes de ayuntamientos en el estado de Michoacán, regido por el sistema de partidos políticos, por uno basado en el sistema de usos y costumbres. El 9 de septiembre, el IEEM respondió señalando que no tenía atribuciones para resolver la petición. Ante esta respuesta, poco más de 2300 ciudadanos de Cherán decidieron expresar su inconformidad promoviendo per saltum $^{9}$ (Báez y Cienfuegos, 2009), un juicio para la protección de sus

9 Los miembros de la comunidad invocaron la figura de la acción per saltum (saltándose al Tribunal Electoral del Estado de Michoacán), pues consideraban que si el IEEM 
Esta revista forma parte del acervo de la Biblioteca Jurídica Virtual del Instituto de Investigaciones Jurídicas de la UNAM

derechos político-electorales. Para ello, acudieron a la Sala Regional del TEPJF, correspondiente a la Quinta Circunscripción Plurinominal Electoral, con sede en Toluca.

Los ciudadanos de Cherán consideraban que la respuesta del IEEM les impedía ejercer a cabalidad sus derechos político-electorales, pues como miembros de una comunidad indígena tenían derecho a elegir a sus representantes de acuerdo a sus prácticas tradicionales. Desde esa perspectiva, argumentaban que la respuesta del IEEM los marginaba de la justicia estatal, pues a su parecer la libre determinación de los pueblos indígenas, contemplada en el artículo 4o. constitucional, garantiza también el derecho a elegir a sus autoridades de conformidad con sus prácticas tradicionales. Alegaban igualmente que ser residentes de la comunidad y formar parte de la misma eran condiciones suficientes para que las autoridades respetaran las normas consuetudinarias para elegir a sus gobernantes.

El 19 de septiembre la Sala Regional decidió abrir un expediente para estudiar el caso. Ante la dificultad planteada, dos días después, los integrantes de ese órgano colegiado determinaron solicitar su atracción a la Sala Superior del TEPJF, con sede en el Distrito Federal, para lo cual remitió el expediente y sus anexos. El 24 de septiembre la mayoría de los magistrados de la Sala Superior acordaron conocer del asunto, turnando su estudio a la ponencia de su presidente, magistrado Alejandro Luna Ramos, quien presentó un proyecto de resolución el 2 de noviembre, faltando únicamente 10 días para las elecciones de Michoacán. Dicho proyecto ${ }^{10}$ fue aprobado ese mismo día, por una mayoría de seis de los siete magistrados integrantes de la Sala Superior del TEPJF.

no tenía competencia para resolver su planteamiento, tampoco habría recurso en el nivel local para que se reconociera su derecho a elegir autoridades municipales de acuerdo a usos y costumbres y organizarlas conforme a sus prácticas tradicionales. Báez Silva, Carlos y Cienfuegos Salgado, David, "El per saltum en el derecho procesal electoral federal", Boletín Mexicano de Derecho Comparado, año XLII, núm. 126, septiembre-diciembre de 2009, pp. 1201-1236.

10 Tribunal Electoral del Poder Judicial de la Federación, “Juicio para la protección de los derechos político-electorales del ciudadano identificado con la clave SUP/JDC 9167/2011", en $h$ ttp://portal.te.gob.mx/turnos-sentencias/sistemaconsulta?partialfields=¿rrequiredfield $s=\% 2528$ sala\%253ASUP\%7Csala\%253ASG\%7Csala\%253ASM\%7Csala\%253ASX\%7Csa la\%253ASDF\%7Csala\%253AST\%2529ぬsites=sentencias_portal\%7Cturnoserexpediente= Cher\%C3\%A1n\&op=Buscar (consulta 6 de junio de 2012). 
El proyecto del magistrado Luna Ramos parte de reconocer a las 2312 personas que habían promovido el juicio su calidad de miembros de una comunidad indígena purépecha, sin necesidad de mayores elementos, toda vez que así lo habían manifestado. Ello en razón de que la conciencia de la identidad indígena es un criterio fundamental para aplicar las disposiciones sobre pueblos indígenas.

A continuación, afirma que entre los derechos fundamentales de los pueblos indígenas se encuentra el derecho a la libre determinación, en su variante de autogobierno. En tanto derecho fundamental, las autoridades de cualquier tipo están obligadas a promoverlos, respetarlos, garantizarlos, interpretarlos con un criterio extensivo y aplicarlos de acuerdo a los principios de universalidad, indivisibilidad, interdependencia y progresividad.

Por otra parte, invocando la vigencia de la más reciente reforma constitucional en materia de derechos humanos, ${ }^{11}$ señala que en ella se establecieron normas jurídicas que obligan a las autoridades, jurisdiccionales y no jurisdiccionales, a interpretar y aplicar los derechos humanos reconocidos en la Constitución y en los tratados internacionales. En consecuencia, la Sala Superior del TEPJF estaba obligada a considerar en su resolución del caso del municipio de Cherán, no sólo los artículos 1o. y 2o. de la Constitución federal, sino también las disposiciones aplicables de los Pactos Internacionales de Derechos Civiles y Políticos así como de Derechos Económicos, Sociales y Culturales; el Convenio número 169 de la Organización Internacional del Trabajo sobre Pueblos Indígenas y Tribales en Países Independientes, así como la Declaración de las Naciones Unidas sobre los Derechos de los Pueblos Indígenas.

Tomando como fundamento las disposiciones normativas referidas en el párrafo anterior, el proyecto reconocía el derecho de los 2312 ciudadanos de Cherán a autodeterminarse y, por lo tanto, a establecer en cualquier momento la forma de organización más acorde a sus necesidades y prioridades. De acuerdo a lo consignado en la resolución, el derecho al autogobierno trae aparejado el derecho de las comunidades indígenas a determinar en cualquier momento si las elecciones para nombrar a sus autoridades deben llevarse a cabo por el sistema legal ordinario o, por el contrario, con base en los usos y costumbres de la comunidad.

11 Diario Oficial de la Federación, 10 de junio de 2011. 
Esta revista forma parte del acervo de la Biblioteca Jurídica Virtual del Instituto de Investigaciones Jurídicas de la UNAM

Agregaba que la inexistencia de normas aplicables en la Constitución local no resultaba relevante pues al tratarse de una materia regulada en la Constitución federal y en instrumentos internacionales suscritos y ratificados por el gobierno federal, cuentan con un carácter imperativo, de orden público, de obediencia inexcusable e imposible renuncia. En consecuencia, aun cuando el autogobierno de los pueblos indígenas no esté contemplado en la Constitución y leyes locales, lo importante es que lo esté en la Constitución federal.

De acuerdo a la interpretación contenida en la resolución, la Constitución federal articula una serie de elementos (contenidos en los artículos 39, 40, 41, 115 y 116), que desarrollan y garantizan el carácter republicano, representativo y democrático de sus instituciones, consignando los principios para que las elecciones sean democráticas y resultado del ejercicio soberano del pueblo. Al estar incluidos en la Constitución federal adquieren una naturaleza imperativa, de orden público, de obediencia inexcusable e irrenunciable, por lo cual no precisan estar incluidos en las Constituciones locales para prevalecer. Apunta que el principio democrático requiere que permita la manifestación de la pluralidad de la población, de manera que las distintas visiones y proyectos de nación puedan ser articulados políticamente.

Siguiendo ese orden de ideas, la resolución constata que en los últimos años se ha venido dando una serie de cambios en las normas constitucionales y legales orientadas a revertir la situación de marginalidad de la población indígena. Valorando que las garantías individuales gozadas por todas las personas no han sido suficientes para un adecuado desarrollo individual y colectivo de las poblaciones indígenas, señala que el legislador constituyente ha reconocido que los derechos de esos pueblos y comunidades son indispensables para su existencia, bienestar y desarrollo integral. En consecuencia, el hecho de que no exista un procedimiento en la legislación michoacana para atender la petición de los habitantes del municipio de Cherán, no puede ser motivo para que no ejerzan un derecho humano contemplado en la Constitución federal.

Por otra parte, la resolución señala la existencia de ciertos límites al autogobierno. El primero consiste en la prohibición de costumbres e instituciones incompatibles con los derechos fundamentales definidos por el sistema jurídico nacional y en los derechos humanos internacionalmente reconocidos. El segundo afirma que la aplicación de los usos y costumbres en los procesos comiciales no debe interpretarse 
Esta revista forma parte del acervo de la Biblioteca Jurídica Virtual del Instituto de Investigaciones Jurídicas de la UNAM

como una licencia para convalidar situaciones o conductas tendentes a perpetuar viejas desigualdades que tradicionalmente han perjudicado a individuos o minorías dentro de las comunidades indígenas. A ese respecto, cuando los usos y costumbres impliquen actividades que alteren la universalidad del voto, se les considerará inválidas.

Tomando en cuenta lo anterior, el proyecto, aprobado por seis de los siete magistrados de la Sala Superior del TEPJF, arribaba a varias resoluciones. Para empezar revocaba el acuerdo del IEEM del 9 de septiembre de 2011 donde señalaba su carencia de atribuciones para responder la petición de los habitantes del municipio de San Francisco Cherán para nombrar a sus autoridades con bases en sus usos y costumbres. Igualmente, determinó que los integrantes de dicha comunidad tenían el derecho a solicitar la elección de sus autoridades con base en sus normas, procedimientos y tradiciones, con respeto a los derechos humanos. De manera paralela, dejó sin efectos los acuerdos de las autoridades electorales michoacanas relacionados con la elección de integrantes del Ayuntamiento del municipio de Cherán orientados a preparar y organizar las elecciones de acuerdo al régimen de partidos políticos.

Asimismo, la resolución ordenó que el IEEM, en su calidad de máxima autoridad electoral en Michoacán, tomara las medidas conducentes para realizar una consulta en el municipio a fin de determinar si la mayoría de los integrantes de la comunidad estaban de acuerdo en celebrar los comicios bajo el sistema de usos y costumbres, al tiempo que, reconociendo la imposibilidad de celebrar elecciones el 13 de noviembre, le ordenaba que se llevaran a cabo en diversa fecha. Igualmente, de considerar que había condiciones para celebrar comicios, le instruía a someter al Congreso local los resultados de la consulta a fin de que la autoridad legislativa emitiera un decreto que señalara la fecha de la elección y de la toma de posesión de las nuevas autoridades. Una vez emitida la resolución legislativa, ordenaba al IEEM a tomar las medidas adecuadas a fin de establecer las condiciones de diálogo y consenso necesarios para realizar las elecciones por usos y costumbres. Finalizaba señalando que, si para el 1o. de enero de 2012 no se había determinado quién sería la autoridad municipal de Cherán, el IEEM debía informar de ello al Congreso local para que este último designara a las autoridades provisionales, respetando para ello el derecho de consulta de la comunidad. 
Esta revista forma parte del acervo de la Biblioteca Jurídica Virtual del Instituto de Investigaciones Jurídicas de la UNAM

Hay varios puntos a subrayar en relación con el contenido de la sentencia de la Sala Superior del TEPJF sobre Cherán. Para comenzar, resulta singular que la sentencia no profundice respecto a si las disposiciones propias de los pueblos indígenas deben aplicarse únicamente a quienes lo solicitaron o al total de los electores pues, de acuerdo a la información oficial, los promoventes representaban tan solo el 16.9\% de los ciudadanos empadronados en el municipio de Cherán, es decir, una minoría.

Por otra parte, no se aprecia en ninguna parte la más mínima mención al acuerdo de la asamblea general celebrada el 1o. de junio de 2011, por medio del cual los habitantes decidieron impedir que las autoridades electorales locales ejercieran sus facultades. Haciendo a un lado la elección de las autoridades municipales, sin entrar en cuestiones relativas a la posible responsabilidad penal, en la práctica el silencio del tribunal convalidó una situación irregular pues a los habitantes de Cherán se les impidió participar en el proceso para elegir gobernador y diputados locales que se llevó a cabo en el resto de Michoacán.

Igualmente, hay una objeción íntimamente ligada a la naturaleza federal del Estado mexicano. Como quedó establecido anteriormente, las entidades federativas que reconocen los usos y costumbres como modalidad para elegir autoridades en los municipios donde la población indígena es predominante, han incluido invariablemente ese reconocimiento en sus Constituciones locales. Precisamente uno de los aspectos más llamativos del problema planteado por los habitantes del municipio de Cherán residía en que el reconocimiento que demandaban no estaba contemplado en la Constitución michoacana.

Hasta antes de esta resolución, la inclusión de los usos y costumbres se había contemplado en las Constituciones locales donde, además, se creaban instrumentos e instituciones, así como garantías jurídicas de que dicha inclusión no contravendría el sentido de los principios contenidos en la Constitución federal y en la local. Sin ánimo de disculpar la actuación del IEEM en el caso, ante la ausencia de regulaciones sobre los usos y costumbres aplicados al ámbito electoral en la Constitución local, dicho organismo carecía de parámetros que regularan su actuación.

La sentencia del caso Cherán también puede ser vista como un asunto en el que el tribunal electoral federal se extralimitó en el ejercicio de sus facultades. En efecto, la litis en el juicio consistía en determinar si el Consejo General del IEEM era competente para resolver la solicitud 
Esta revista forma parte del acervo de la Biblioteca Jurídica Virtual del Instituto de Investigaciones Jurídicas de la UNAM

planteada por los 2312 habitantes de Cherán para que declarara si esa comunidad podía elegir a sus autoridades municipales con base en los usos y costumbres. Como quedó asentado líneas arriba, el IEEM carecía de competencia para declarar, de acuerdo a la Constitución y las leyes de Michoacán, si dicha comunidad podía celebrar elecciones utilizando los usos y costumbres.

Considerando la normativa vigente en las entidades federativas donde se regulan los usos y costumbres para elegir a las autoridades, el órgano estatal competente para resolver la demanda formulada por los habitantes de Cherán era el Congreso del Estado de Michoacán ${ }^{12}$ para que, en ejercicio de la soberanía popular, determinara lo que fuera procedente. Así, el órgano competente para resolver la solicitud de los 2312 habitantes de Cherán orientada a modificar el sistema de partidos políticos para adoptar el sistema de usos y costumbres no era la Sala Superior del TEPJF cuya actuación debería haberse limitado a hacer del conocimiento del Congreso michoacano la solicitud planteada. ${ }^{13}$

\section{Conclusiones}

El análisis de la solicitud de los habitantes del municipio de Cherán para nombrar a sus autoridades con base en el sistema de usos y costumbres, propio de las comunidades indígenas, debe tomar en cuenta dos hechos que condicionaron tanto la conducta de los miembros de la comunidad como la respuesta de los magistrados de la Sala Superior del TEPJF.

12 El artículo 2o. de la Constitución federal asienta: "El derecho de los pueblos indígenas a la libre determinación se ejercerá en un marco constitucional de autonomía que asegure la unidad nacional. El reconocimiento de los pueblos y comunidades indígenas se hará en las constituciones y leyes de las entidades federativas...."

13 Esta conclusión es coincidente con los argumentos del magistrado Flavio Galván Rivera, único disidente del proyecto presentado por el magistrado Luna Ramos, expresados en su voto particular. Véase Tribunal Electoral del Poder Judicial de la Federación, "Voto particular que con fundamento en el último párrafo del artículo 187 de la Ley Orgánica del Poder Judicial de la Federación emite el magistrado Flavio Galván Rivera en el Juicio para la protección de los derechos político-electorales del ciudadano identificado con la clave SUP/JDC 9167/2011", Loc. cit, 
Esta revista forma parte del acervo de la Biblioteca Jurídica Virtual del Instituto de Investigaciones Jurídicas de la UNAM

Por una parte, no puede olvidarse la situación de violencia padecida por la comunidad que, harta de la impotencia o la complicidad de las autoridades municipales y estatales ante los despojos a su patrimonio y las agresiones a los habitantes que se oponían, decidió tomar la seguridad pública en sus propias manos. Al haber dado un primer paso de desconocimiento de los gobernantes, la solicitud de escoger a sus autoridades sin intervenciones foráneas aparece como una consecuencia lógica.

Por otra parte, la coyuntura electoral influyó poderosamente en las respuestas de los actores involucrados. Al plantear su solicitud faltando menos de seis meses para la jornada comicial, los habitantes de Cherán disminuyeron el margen de maniobra de los actores políticos involucrados. Es cierto que el IEEM carecía de facultades para responder la demanda de la comunidad, pero también lo es que no canalizó la solicitud al Congreso michoacano, ni este último hizo un intento por intervenir.

La urgencia por encontrar una respuesta explica también la decisión de plantear la controversia en el ámbito electoral federal, sin haber agotado previamente la jurisdicción local. Igualmente, cuando la Sala Superior del TEPJF decidió admitir la solicitud de algunos de los pobladores de Cherán faltaban menos de ocho semanas para que las elecciones locales tuvieran lugar. Por si esto fuera poco, hay que tener en mente que el proceso electoral de Michoacán constituía la última elección local antes de los comicios federales de julio de 2012. Así, el resultado en Michoacán se interpretaría como un ensayo de lo que podría ocurrir en el ámbito federal. En razón de ello, se entiende que las actuaciones se hayan realizado contra el reloj.

Independientemente de los posibles beneficios que para la comunidad de Cherán pudo haber representado la adopción del sistema de usos y costumbres, al haber respondido el TEPJF de manera afirmativa la solicitud del $16.9 \%$ de los ciudadanos empadronados, parecería como si la aplicación de las disposiciones sobre pueblos indígenas viniera a ser un derecho de minorías que le es aplicable no sólo a ellas sino a la totalidad de la comunidad. Por sus consecuencias, es un asunto que merece ser reflexionado.

Ahora bien, llama poderosamente la atención que la sentencia del TEPJF no haga referencia a la posible violación de los derechos político-electorales de los habitantes de esta comunidad de la Sierra Purépecha que, dado que la asamblea general de Cherán había prohibido 
que el IEEM ejerciera su competencia en esa demarcación territorial, les impidió votar para elegir al gobernador del estado así como al diputado del VII distrito local. En ambas elecciones, poco más de 13000 votos no fueron considerados. No nos parece una cuestión menor.

Finalmente, al invocar la reforma en materia de derechos humanos para resolver la solicitud de los habitantes de Cherán, los magistrados federales indebidamente sustituyeron un papel que corresponde a los legisladores locales como representantes directos de la voluntad popular. Hasta antes de esta resolución, los usos y costumbres aplicados a los procesos electorales estuvieron precedidos de un proceso deliberativo orientado a crear una serie de leyes capaces de garantizar que su inclusión no estaría contraviniendo los principios constitucionales federales y locales. Es el caso de Oaxaca, Tlaxcala y Chiapas. En Michoacán, por virtud de la sentencia analizada, este proceso estuvo ausente. Esto pone en evidencia una actuación desmesurada del tribunal electoral federal.

Independientemente de la discusión acerca de la competencia y jurisdicción entre las diferentes autoridades electorales, hay que tener en mente que el ejercicio del poder tiene un impacto considerable sobre los derechos de los ciudadanos y, en consecuencia, sobre las condiciones en que se ejerce la democracia.

En ese sentido, la resolución del TEPJF en el caso de Cherán puede en el futuro cercano formar jurisprudencia en materia electoral. De ser así, serviría como punta de lanza para que casos de conflictos latentes entre las comunidades indígenas y los gobiernos locales se diriman por la vía jurisdiccional federal, amenazando la gobernabilidad local, en razón de que sea una autoridad federal quien tome decisiones por encima de la soberanía de las entidades federativas. Sin adelantar ninguna conclusión, consideramos que, a partir de Cherán, se abren nuevas aristas respecto a la adopción del sistema de usos y costumbres para designar a las autoridades en las comunidades indígenas y la vigencia de los principios democráticos en México.

\section{Bibliografía}

Arenas Bátiz, Emilio, Reflexiones en torno a la integración y prueba del derecho electoral consuetudinario indígena, México, IFE, 2003. 
Armenta Ramírez, Petra, "Elecciones por usos y costumbres en México", en www.letrasjuridicas.com/.../14/armenta14.pdf (consultado 25 Agosto 2012).

Báez Silva, Carlos y Cienfuegos Salgado, David, "El per saltum en el derecho procesal electoral federal", Boletín Mexicano de Derecho Comparado, año XLII, núm. 126, septiembre-diciembre de 2009, pp.1201-1236.

Castillo Vaquera, Jorge G. e Ibarra Romo, Mauricio I., "Participación electoral femenina en contextos de usos y costumbres: el caso de Eufrosina Cruz", Veredas, 24, año 13, 1er. semestre, 2012.

Fix-Fierro, Héctor, Los derechos políticos de los mexicanos, 2a. ed. México, UNAM, Instituto de Investigaciones Jurídicas, 2006.

López Bárcenas, Francisco, "Elecciones por usos y costumbres en Oaxaca”, en Calvo Barrera, Raúl y Cienfuegos Salgado, David (coords.), Derecho electoral de las entidades federativas mexicanas, Chilpancingo, Tribunal Electoral del Estado de Guerrero y Fundación Académica Guerrerense, 2006, en http://biblio.juridicas.unam. $m x /$ libros/6/2980/pl2980.htm (consultado el 25 de agosto de 2012).

Renard, Marie-Christine, 1994, "Le Chiapas est aussi le Mexique, neo-zapatisme et changement politique", Cahiers des Amériques Latines, núm. 17, París, Institut des Hautes Etudes de l'Amérique Latine (IHEAL).

Tribunal Electoral del Poder Judicial de la Federación, “SUP/JDC 9167/2011", en http://portal.te.gob.mx/turnos-sentencias /sistemaconsulta?partialfields $=\&$ requiredfields $=\% 2528$ sala $\% 253 \mathrm{AS}$ UP\%7Csala\%253ASG\%7Csala\%253ASM\%7Csala\%253ASX\%7Csal a\%253ASDF\%7Csala\%253AST\%2529\&sites=sentencias_portal\%7C turnoserexpediente $=$ Cher\%C3\%A1nఓ $\%=$ Buscar.

Viqueira, Juan Pedro y Sonnleitner, Willibald (coords.), Democracia en tierras indígenas. Las elecciones en Los Altos de Chiapas (1991-1998), El Colegio de México-CIESAS-IFE, 2000. 